\title{
O PLANEJAMENTO EXPERIMENTAL DOEHLERT NA CARACTERIZAÇÃO DA RUGOSIDADE COMO FUNÇÃO DOS PARÂMETROS DE ENTRADA DO PROCESSO DE FRESAMENTO DO AÇO ABNT 1020
}

\section{DOEHLERT EXPERIMENTAL DESIGN IN THE ROUGHNESS EVALUATION AS A FUNCTION OF MILLING MACHINING INPUT PARAMETERS OF THE ABNT 1020 STEEL}

\author{
L. BENINI ${ }^{1 *}$ e M. A. C. ROSSI ${ }^{2}$
}

${ }^{1}$ Universidade Federal de Viçosa, Departamento de Engenharia de Produção e Mecânica, Viçosa, Minas Gerais, Brasil

${ }^{*}$ Autor correspondente. Universidade Federal de Viçosa, Departamento de Engenharia de Produção e Mecânica, Viçosa, Minas Gerais, Brasil, Phone: +55 31 36126500

Endereço de e-mail: lucasbenini@gmail.com (L. Benini).

\section{A R T I C L E I N F O}

Article history:

Received 2018-11-15

Accepted 2018-12-20

Available online 2019-08-20

palavras-chave

Planejamento Doehlert

Fresamento

Modelo Matemático

Rugosidade

keywords

Doehlert experimental design

Milling machining process

Mathematical model

Roughness

\begin{abstract}
R E S U M O
Este trabalho visa a obtenção de um modelo matemático capaz de descrever o comportamento da rugosidade do aço ABNT 1020 em função aos parâmetros de entrada do processo de fresamento convencional. Para isso, foi empregado a metodologia de planejamento experimental denominada planejamento Doehlert. Foram definidas 5 velocidades de corte e 3 velocidades de avanço, que foram correlacionadas, formando 7 pares de parâmetros de entrada. Assim, foram obtidos 3 modelos de caracterização para os parâmetros Ra, Rz e Rt que possuem uma assertividade de 67,3\%, 70,9\% e 78,3\% respectivamente. Entretanto, pôde-se concluir que, apesar possuírem um $R^{2}$ maior de $60 \%$, este resultado pode ser considerado não aceitável em termos do objetivo deste trabalho, uma vez que o padrão definido foi em torno de 95\%, o que o torna inviável para o caso do fresamento.
\end{abstract}

A B S T R A C T

This work aims to obtain a mathematical model capable of describing the roughness behavior of ABNT 1020 steel as a function of the input parameters of the conventional milling process. To do this, was used the methodology called Doehlert experimental design. Five cutting speeds and 3 feed rates were defined, which were correlated, forming 7 pairs of input parameters. Thus, 3 characterization models were obtained for the roughness parameters $R a, R z$ and $R t$, that presented an assertiveness of $67.3 \%, 70.9 \%$ and $78.3 \%$ respectively. However, it can be concluded that, despite having an $R^{2}$ greater than $60 \%$, this result can be considered not acceptable in terms of the objective of this work, since the defined pattern was around 95\%, which makes it unfeasible for the case of milling machining process. 


\section{INTRODUÇÃO}

Peças fabricadas através de processos primários de fabricação, como o processo de fundição e de conformação usualmente, ao final do processo, possuem uma superfície mais rústica, necessitando, muitas vezes, de algum tipo de acabamento para que fique adequada ao uso. Além disso, estes processos possuem certas limitações de forma, sendo difícil a obtenção de aspectos geométricos na peça, como roscas, saliências, reentrâncias e afins. Assim, acabam por não apresentar em muitos casos o melhor custo $\mathrm{x}$ benefício em termos de fabricação. $O$ processo de usinagem permite o alcance destes objetivos, sendo possível obter geometrias complexas com um bom custo benefício (Chiaverini, 1986). Compreende-se como usinagem todo aquele processo que modela, dimensiona e/ou dá acabamento superficial à peça produzindo cavaco. Define-se como cavaco o resíduo material retirado da peça pela ferramenta, que se caracteriza por sua geometria irregular (Ferraresi, 1977).

A otimização dos parâmetros de corte em usinagem está limitada, em grande parte, à escolha correta da ferramenta com base em avanços, profundidades de usinagem e velocidades de corte indicados por fontes que publicam a experiência acumulada no assunto, geralmente catálogos de fabricantes (Diniz et al., 1989. apud Freitas, 2015). A determinação dos parâmetros otimizados é feita de maneira empírica e não existe, ainda, um método preciso de se prever a rugosidade de uma peça como consequência dos parâmetros de cortes determinados. Uma consequência disso é que, apesar de a usinagem ser um processo em que a precisão dimensional e o acabamento superficial sejam considerados bons, ainda seja preciso algum tipo de arremate seja feito para que peça esteja apropriada para o uso.

Assim, prever estes parâmetros é de extrema importância econômica, uma vez que permite otimizar o processo, diminuindo etapas e, consequentemente, o tempo de produção. Ademais, permite a melhora da precisão de projeto, o que resulta em peças melhor acabadas. No planejamento Doehlert, é possível se analisar duas, três ou mais variáveis, com um reduzido número de ensaios, se comparado com outras metodologias de planejamento experimental. Cada valor das variáveis a serem analisadas poderão ser organizadas numa forma matricial, utilizando-se os coeficientes matriciais de Doehlert.

Uma das grandes vantagens do planejamento experimental Doehlert é a necessidade de um número reduzido de testes experimentais, sem necessariamente perder a qualidade das respostas obtidas. Isso torna esta metodologia de fácil aplicação em chão de fábrica, reduzindo drasticamente o tempo para a obtenção de tais parâmetros, aumentando a economia, bem como a precisão dos processos de usinagem. Além disso, com uma maior precisão na obtenção da rugosidade ideal, alcançando parâmetros mais próximos do desejado, a quantidade de trabalho para acabamentos e superacabamentos acaba por fim por também diminuir, o que se refletirá no custo de produção.

Este trabalho tem como objetivo a obtenção de um modelo matemático capaz de descrever o comportamento da rugosidade superficial em relação aos parâmetros de entrada do processo de fresamento na usinagem de uma peça. Para tanto, foi empregada a metodologia de planejamento experimental Doehlert. Como objetivos específicos têm-se:

- Obter os resultados de rugosidade do fresamento frontal de uma peça de aço ABNT 1020;

- Aplicar a metodologia de regressão linear múltipla e o planejamento experimental Doehlert para a obtenção de um modelo matemático que caracterize $o$ comportamento da rugosidade superficial no fresamento do aço ABNT 1020;

- Comparar os modelos matemáticos e determinar o modelo mais adequado para melhor caracterização dos parâmetros.

\section{PROCESSO DE FRESAMENTO}

Compreende-se como usinagem todo aquele processo que modela, dimensiona e/ou dá acabamento superficial à peça produzindo cavaco. Define-se como cavaco o resíduo material retirado da peça pela ferramenta, que se caracteriza por sua geometria irregular. Existem diversos processos de usinagem como por exemplo: fresamento, torneamento, aplainamento, furação, alargamento, mandrilamento, serramento, brochamento, retificação, brunimento e fresamento (Ferraresi, 1977; Machado et al., 2009; Diniz et al., 2010; Groover, 2017).

O processo de fresamento é um processo de fabricação mecânico de usinagem que visa obter superfícies através da utilização de ferramenta cilíndricas, geralmente multicortante. Para tal, a mesma gira em torno de seu próprio eixo e a peça ou a própria ferramenta se desloca de acordo com uma trajetória qualquer, a fim de se realizar o corte. Esta metodologia de desbaste pode ser classificada em dois tipos básicos: fresamento frontal e fresamento cilíndrico tangencial (Ferraresi, 1977).

O fresamento frontal é um processo utilizado para a obtenção de superfícies planas perpendiculares ao eixo de rotação da ferramenta, como mostra a Figura 1 (Groover, 2017).

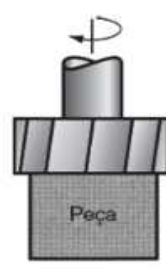

(a)

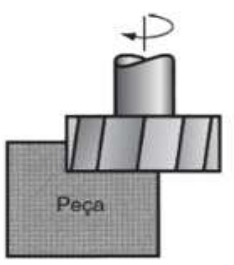

(b)

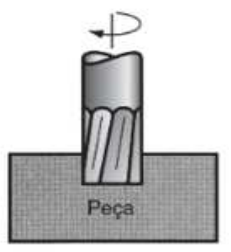

Figura 1 - (a) Fresamento de faceamento convencional (b) Fresamento de faceamento parcial (c) Fresamento de topo (Groover, 2017).

Já o fresamento cilíndrico tangencial é destinado a obtenção de uma superfície plana paralela ao eixo de rotação da ferramenta como mostra a Figura 2. O fresamento tangencial pode ser concordante ou discordante. $\mathrm{O}$ primeiro ocorre quando o movimento de avanço possui o mesmo sentido do movimento rotatório da ferramenta. Já no segundo, o movimento é contrário à rotação da fresa. 


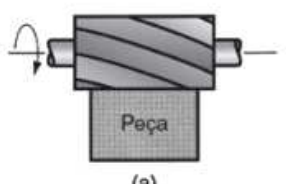

(a)

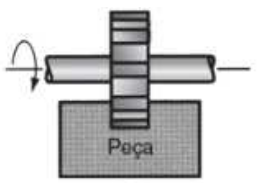

(b)

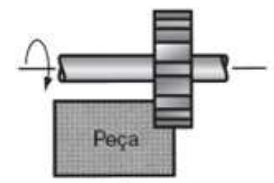

(c)

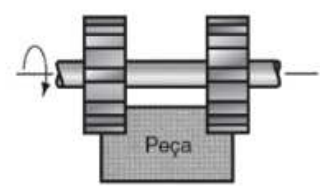

(d)

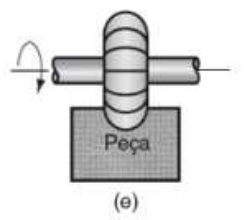

Figura 2 - (a) Fresamento tangencial de face. b)

Fresamento de canais (c) Fresamento de rasgos (d) Fresamento de rasgos paralelos (e) Fresamento de perfil (Groover, 2017).

\subsection{Rugosidade}

O acabamento de uma superfície usinada é a combinação de vários fatores que podem ser divididos em rugosidade, ondulações e falhas (Sata, 1963; Drozda e Wick, 1983; Juneja e Swkhon, 1987; Shaw, 1984; Schaffer, 1988). Cada componente de uma peça exige determinado nível de acabamento superficial, que deve estar prevista em projeto (Machado et al., 2009). Segundo Kalpakjian (1995), os seguintes fatores devem ser levados em conta na determinação do acabamento superficial: grau de acoplamento entre componentes; coeficiente de fricção, desgaste e lubrificação; resistência à fadiga e à corrosão; resistividade elétrica e térmica de contato; processamento posterior, como pintura; aparência; custo.

Ondulações são irregularidades superficiais ou erros geométricos cujos espaçamentos são maiores que as chamadas rugosidades. Suas causas podem ser vibrações, flexão da peça ou da ferramenta, temperatura de corte e erros de fixação da peça ou ferramenta. Falhas são descontinuidades na topográfica usual de uma determinada superfície. São involuntárias, inesperadas e não desejáveis. Podem ser causadas por defeitos intrínsecos, como inclusões, bolhas, trincas, ou podem surgir durante o fresamento. Rugosidade pode ser definida como irregularidades finas ou erros microgeométricos resultantes do processo de corte. Seu perfil pode ser resultado d vários parâmetros, como: máquinaferramenta, propriedades do material da peça, geometria e material da ferramenta e operação de usinagem. É muitas vezes utilizada como critério de saída para controle da usinagem (Machado et al., 2009).

Quantificação da Rugosidade: existem dois sistemas básicos para quantificação da rugosidade: o da linha média $\mathrm{M}$ e o da envolvente E. O mais adotado até hoje tem sido o sistema M. No sistema M, todos os pontos de medição são tomados com relação a uma linha média, cuja soma das áreas superiores a esta linha seja igual à soma das áreas inferiores (Agostinho, 2004), conforme mostra a Figura 3.

Outro critério adotado para a quantificação da rugosidade é o comprimento de amostragem $\left(l_{e}\right)$ ou cut off. $\mathrm{O}$ cut off é uma porção do chamado comprimento total de avaliação $\left(l_{m}\right)$. É a região onde a medição da rugosidade é efetivamente realizada, descartando-se os dados adquiridos nas porções imediatamente anterior e posterior. A Figura 4 ilustra o comprimento $l_{e}$ e $l_{m}$.

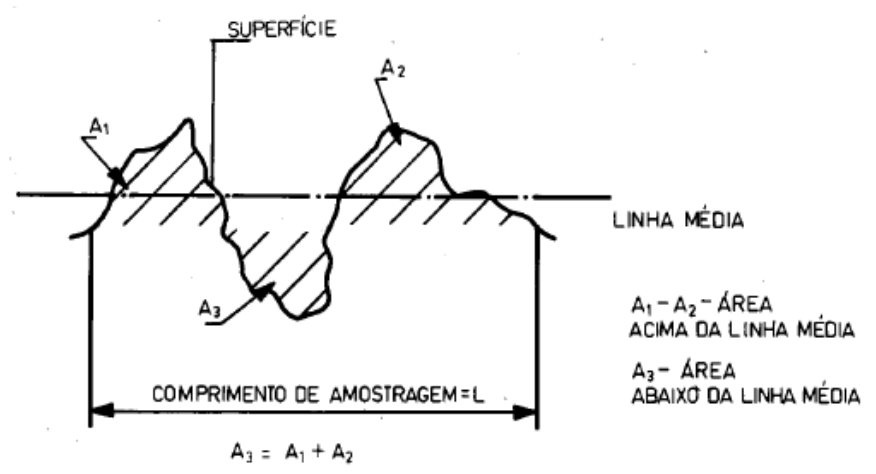

Figura 3 - Linha média (Agostinho, 2004).

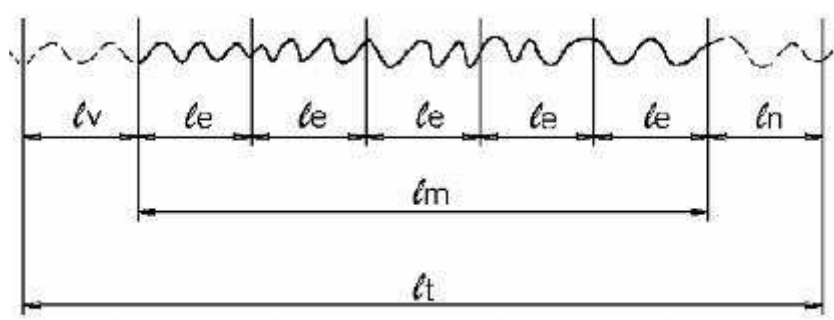

Figura 4 - Comprimentos de rugosidade (Rosa, 2006).

No Brasil, a Norma ABNT NBR ISO 4287 (2002) apresenta os principais parâmetros empregados na quantificação da rugosidade. A Tabela 1 reúne os mais utilizados.

Tabela 1 - Composição química média do aço ABNT 1020. Parâmetro Definição

Desvio aritmético Média aritmética dos valores absolutos médio $\mathrm{Ra}$

Rugosidade máxima Ry das ordenadas no comprimento de amostragem.

Rugosidade total Está definido como o maior valor das rugosidades parciais que se apresenta no percurso de medição.

$\mathrm{Rt}$

Corresponde à distância vertical entre o pico mais alto e o vale mais profundo no comprimento de avaliação.

Rugosidade média Corresponde à média aritmética dos $\mathrm{Rz}$ cinco valores de rugosidade parcial.

\subsection{Planejamento Experimental Doehlert}

Quando se deseja explorar a relação entre uma resposta y e um número $\mathrm{n}$ de variáveis $\mathrm{x}_{1}, \mathrm{x}_{2}, \mathrm{x}_{3}, \ldots, \mathrm{x}_{\mathrm{n}}$, uma região em um espaço com $n$ dimensões é definida pela combinação destas variáveis, $\mathrm{x}_{1}, \mathrm{x}_{2}, \mathrm{x}_{3}, \ldots, \mathrm{x}_{\mathrm{n}}$, com cada resposta y (Doehlert, 1970). No planejamento Doehlert, é possível se analisar duas, três ou mais variáveis, obtendo-se um domínio circular, esférico e hiperesférico, respectivamente (Novaes, 2017). No modelo de análise para duas variáveis, uma matriz é formada contendo um ponto central e seis pontos distribuídos, formando-se um hexágono regular, como mostra a Figura 13.

O hexágono de Doehlert parte de três pontos para a sua formação: $a, b$, e c. estes pontos podem ser traduzidos em coordenadas como sendo $(0 ; 0),(1,000 ; 0)$ e $(0,500 ; 0,866)$, respectivamente. Subtraindo-se cada ponto um do outro, completa-se o hexágono com os 4 pontos restantes: $(-1,000 ; 0)$, $(-0,500 ;-0,866),(0,500 ;-0,866)$ e $(-0,500 ; 0,866)$ (Doehlert, 1970). 


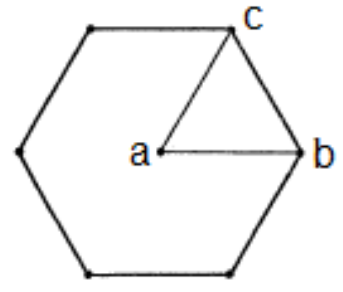

Figura 5 - Hexágono de Doehlert (Doehlert, 1970).

Cada valor das variáveis a serem analisadas poderão, posteriormente, serem codificadas e apresentadas na forma de uma matriz $7 \times 2$, utilizando-se os coeficientes matriciais de Doehlert. Ainda, o modelo definido por Doehlert se torna uma alternativa muito prática e econômica comparado a outros modelos. Isso porque, embora não seja ortogonal, isto não refletirá em perda de qualidade no seu uso efetivo em procedimentos de análise e otimização (Novaes, 2017). Para execução desse modelo de planejamento, o número de experimentos deve ser igual a $\mathrm{k}^{2}+\mathrm{k}+\mathrm{pc}$, onde $\mathrm{k}$ é o número de fatores e pc é a quantidade de experimentos no ponto central (Teófilo e Ferreira, 2006 apud Fabrino, 2008).

Gonçalves et al. (2015) utilizaram esta metodologia no mapeamento dos parâmetros de corte para o torneamento do aço ABNT 1045 utilizando óleo vegetal como fluido de corte. Os resultados obtidos foram extremamente satisfatórios. Além disso, outro trabalho semelhante com o realizado por Gonçalves et al. (2015) foi o experimento comandado por Rodrigues et al. (2018), em que foi feita uma análise da rugosidade em função dos parâmetros de corte utilizando a metodologia do planejamento experimental Doehlert no processo de torneamento do aço ABNT 1045. Os resultados deste trabalho foram semelhantes dos resultados obtidos por Gonçalves et al. (2015), o que indica a eficácia desta metodologia. Além disso, o planejamento experimental Doehlert é amplamente utilizado na área química e médica, como fizeram Teófilo e Ferreira (2006) na obtenção de planilhas para planejamento experimental em quimioterapia, e Fabrino (2008) na determinação de metais em soro e sangue humano.

\section{METODOLOGIA}

Os ensaios foram realizados no Laboratório das Engenharias (Labenge) da UFV, onde se utilizou das infraestruturas dos Laboratórios de Usinagem, de Metalografia e de Metrologia. A máquina-ferramenta utilizada foi a fresadora fabricada pela empresa Diplomat, modelo FVF 3000 (Figura $X$ ), que possui curso de mesa de $1080 \mathrm{~mm}$ no eixo $\mathrm{X}$ (longitudinal), $415 \mathrm{~mm}$ em Y (transversal) e $440 \mathrm{~mm}$ em Z (vertical); possui um motor principal trifásico com potência de acionamento de $5 \mathrm{Hp}$. O eixo-árvore possui $105 \mathrm{~mm}$ de diâmetro e sua rotação pode variar de 78 rpm a 4000 rpm.

A ferramenta a ser utilizada foi uma fresa frontal de topo, fabricada pela empresa Indaço ${ }^{\circledR}$ (modelo 1501.1, DIN 844 NA). Esta fresa possui um diâmetro de $10 \mathrm{~mm}, 4$ dentes com corte à direita, comprimento de hélice de $45 \mathrm{~mm}$ e comprimento total de $90 \mathrm{~mm}$, fabricada em aço M2. A Figura 5 mostra esta ferramenta.

O paquímetro que foi utilizado para as medições dos corpos de prova Mitutoyo ${ }^{\circledR}$, modelo quadridimensional, Digimatic Caliper série 500-147 da Mitutoyo ${ }^{\circledR}$, com resolução de 0,01 mm e capacidade de medição de até $200 \mathrm{~mm}$. O rugosímetro que foi utilizado para a obtenção do parâmetro rugosidade $\mathrm{Ra}$ foi o fabricado pela companhia Mitutoyo ${ }^{\circledR}$ modelo SJ-201. Este instrumento possui uma interface RS232C e saída Digimatic. O cut off utilizado foi de $8 \mu \mathrm{m}$.
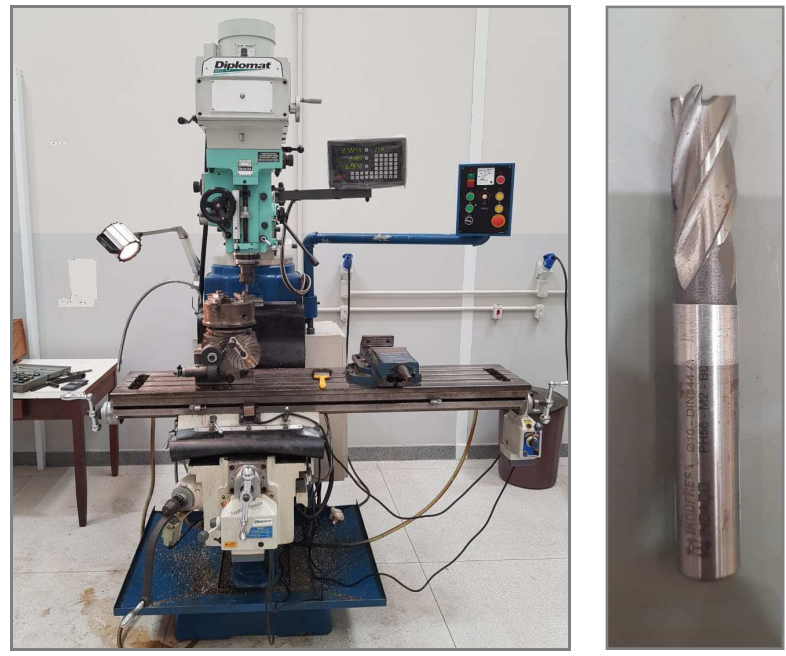

Figura 5 - Máquina ferramenta e fresa.

O material do corpo de prova que foi utilizado nos ensaios é o aço ABNT-1020 disponibilizado pelo Departamento de Engenharia de Produção e Mecânica (DEP) da UFV. A composição química deste aço é fornecida pela NBR NM 87 e está descrita na Tabela 2 (NBR NM 87/2000) e a Figura 6 apresenta analises metalográficas (com ataque de nital) com ampliações de 50x, 100x, 200x e 500x dos corpos de prova.

Tabela 2 - Composição química média do aço ABNT 1020.

\begin{tabular}{cccc}
$\mathrm{C}(\%)$ & $\mathrm{Mn}(\%)$ & $\mathrm{P}(\%)$ & $\mathrm{S}(\%)$ \\
$0,18-0,23$ & $0,30-0,60$ & 0,040 & 0,050 \\
\hline
\end{tabular}

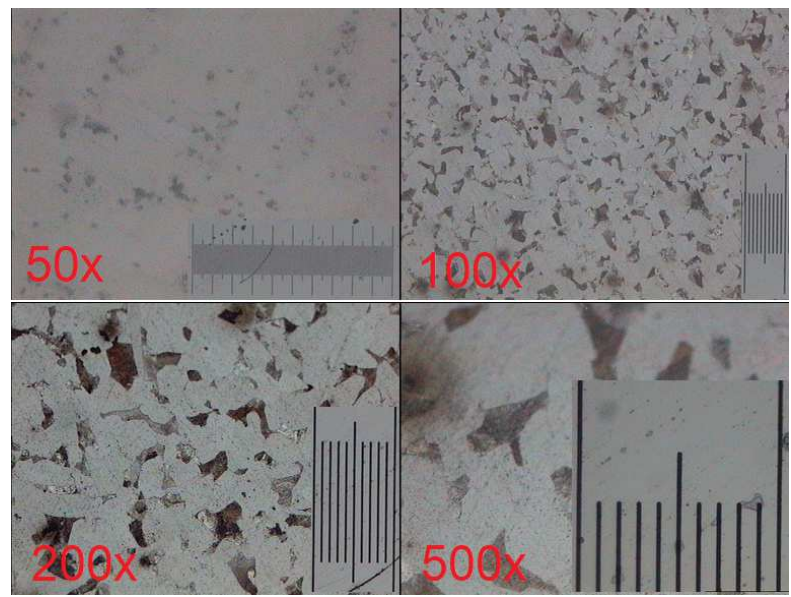

Figura 6 - Micrografia do material com zoom de 50x a 500x.

Foram efetuados ao total 7 ensaios de fresamento, empregando 5 rotações $(\mathrm{N})$ e 3 profundidades de penetração $\left(a_{p}\right)$, selecionados de acordo com as recomendações dos intervalos indicados pelo fabricante da ferramenta. A Tabela 3 mostra os pares $\mathrm{N} x \mathrm{a}_{\mathrm{p}}$. A cada operação de desbaste (passes) do fresamento frontal, foram medidos os valores de $\mathrm{Ra}, \mathrm{Rz}$ e Rt. O corpo de prova teve esses três parâmetros mensurados em cinco pontos diferentes. Assim, foi utilizada uma média dessas cinco medições a fim de minimizar possíveis erros 
estatísticos e de medição dessas variáveis.

Tabela 3 - Parâmetros de usinagem.

\begin{tabular}{|c|c|c|}
\hline Experimento & Rotação $(\mathrm{rpm})$ & Penetração $\mathrm{a}_{\mathrm{p}}(\mathrm{mm})$ \\
\hline 1 & 600 & 1 \\
\hline 2 & 1000 & 1 \\
\hline 3 & 800 & 1,5 \\
\hline 4 & 200 & 1 \\
\hline 5 & 400 & 0,5 \\
\hline 6 & 800 & 0,5 \\
\hline 7 & 400 & 1,5 \\
\hline
\end{tabular}

\subsection{Modelo numérico}

Para a obtenção do modelo numérico foram utilizados modelos polinomiais com e sem interação entre as variáveis, quadráticos e não quadráticos. As Equações de 1 a 4 mostram estes modelos.

$y=b_{o}+b_{1} x_{1}+b_{2} x_{2}$

$y=b_{o}+b_{1} x_{1}+b_{2} x_{2}+b_{3} x_{1} x_{2}$

$y=b_{o}+b_{1} x_{1}+b_{2} x_{2}+b_{3} x_{1}^{2}+b_{4} x_{2}^{2}$

$y=b_{o}+b_{1} x_{1}+b_{2} x_{2}+b_{3} x_{1} x_{2}+b_{4} x_{1}^{2}+b_{5} x_{2}^{2}$

onde $\mathrm{x}_{\mathrm{i}}$ são as variáveis de entrada, $\mathrm{b}_{0}$ é o coeficiente de interseção da regressão linear múltipla, $b_{i}$ são os coeficientes das variáveis independentes de entrada e y é a variável dependente de resposta.

\subsection{Regressão linear múltipla}

Um modelo de regressão que contenha mais de um fator é chamado de regressão linear múltipla. Uma das formas mais práticas de se realizar a regressão linear múltipla é através da abordagem matricial. Podem-se representar os modelos polinomiais na forma matricial conforme mostra a Equação 5 (Montgomery, 2009)

$[Y]=[X][b]$

Onde,

$$
\begin{aligned}
& {[Y]=\begin{array}{c}
y_{1} \\
y_{n}
\end{array}} \\
& {[X]=\left[\begin{array}{ccc}
x_{1} & \cdots & x_{12} \\
\vdots & \cdots & \vdots \\
x_{\mathrm{n} 1} & \cdots & x_{\mathrm{nn}}
\end{array}\right]} \\
& {[b]=\begin{array}{c}
b_{0} \\
b_{1} \\
b_{n}
\end{array}}
\end{aligned}
$$

Assim, pode-se definir o vetor dos coeficientes [b] de acordo com a Equação 9 (Montgomery, 2009).

$$
[b]=\left(X^{\prime} X\right)^{-1} X^{\prime} Y
$$

Porém, atualmente, existem diversos softwares que realizam este cálculo automaticamente, como Statistica ${ }^{\circledR}$, SAS $^{\circledR}$ (Statistical Analysis System), Statigraphics ${ }^{\circledR}$, Minitab $^{\circledR}$,
Design Expert $^{\circledR}$, Modde $^{\circledR}$, Quantum $\mathrm{XL}^{\circledR}$, entre outros (Novaes, 2017).

\section{RESULTADOS}

A Figura 24 apresenta a rugosidade Ra medida nos sete ensaios realizados. Nela estão descritas as médias das medições, bem como o desvio padrão para cada um dos ensaios realizados.

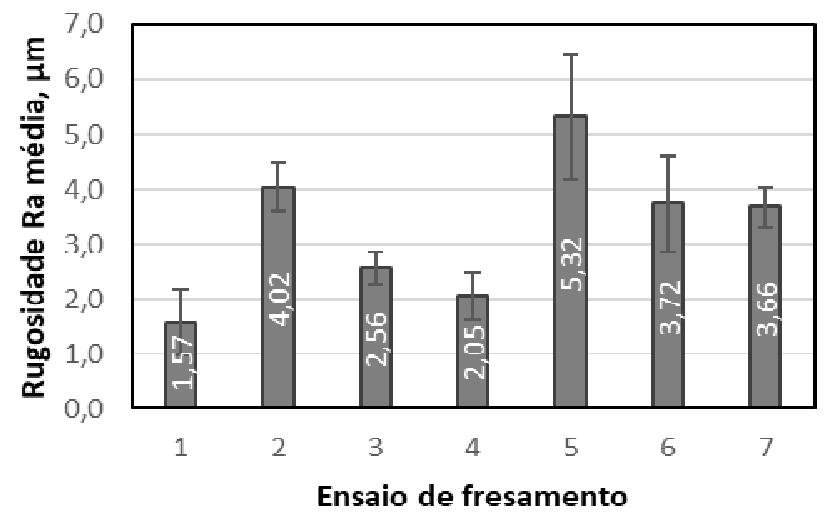

Figura 7 - Rugosidade Ra nos ensaio de fresamento.

Em todos os ensaios ocorreu pelo menos resultado que de rugosidade aleatório. O desvio padrão médio encontrado foi de $19 \%$. Uma das hipóteses que pode explicar este fenômeno é a vibração gerada no processo de desbaste pode ter sido maior em determinado momento.

Os elevados valores dos resultados de rugosidade $\mathrm{Ra}$ foram obtidos nos ensaios em que foi utilizada a menor profundidade de penetração $\left(a_{p}=0,5 \mathrm{~mm}\right)$. Esperava-se $o$ contrário, uma vez que uma maior profundidade $a_{p}$ resulta numa maior área de contato, elevando assim o atrito e, consequentemente, os esforços durante o corte. Entretanto, algumas suposições podem justificar o ocorrido. Como os esforços ficam concentrados mais na ponta da ferramenta em profundidade menores, o momento fletor aumenta, contribuindo ainda mais para o aumento de vibrações. Ademais, o desgaste da ferramenta ou até mesmo falta de precisão da máquina-ferramenta podem ter gerado esta discrepância. A Figura 8 apresenta a rugosidade Rz mensurada nos sete ensaios realizados.

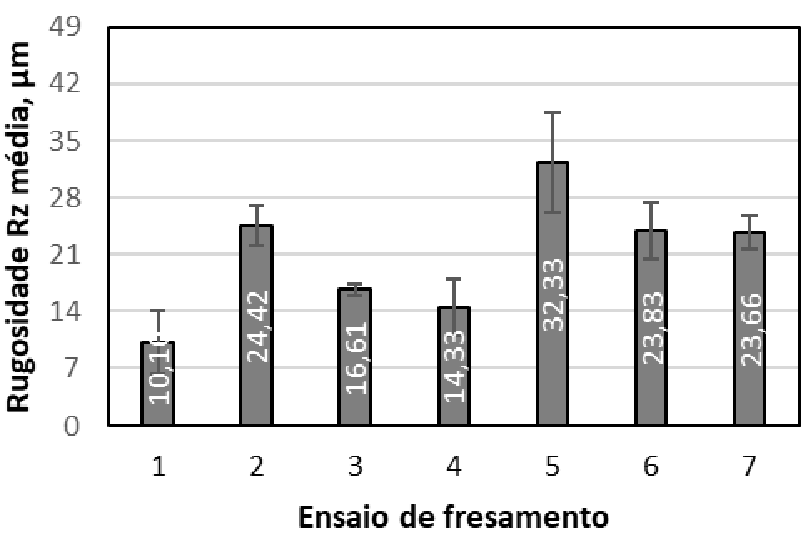

Figura 8 - Rugosidade Rz nos ensaio de fresamento.

Assim como ocorreu nos resultados dos valores do parâmetro Ra, pôde-se observar as discrepâncias semelhantes nas medições do parâmetro Rz. Os altos valores do parâmetro $\mathrm{Rz}$ representam maiores heterogeneidades na superfície das 
amostras. Novamente, com exceção do ensaio número 3, em todos houveram um ou mais resultados de $\mathrm{Rz}$ muito acima ou abaixo da média. Entretanto, devido à quantidade de repetições, estas anomalias se dissolveram entre os resultados.

Como observado nos resultados do parâmetro Ra, os piores resultados (elevados valores do parâmetro $\mathrm{Rz}$ ) foram encontrados nos ensaios em que foram empregados a profundidade de penetração $\left(a_{p}\right)$ de $0,5 \mathrm{~mm}$. Além disso os desvios padrão médio foi de $17 \%$, muito próximo do valor encontrado no parâmetro Ra. A Figura 9 apresenta a os resultados da rugosidade $\mathrm{Rt}$.

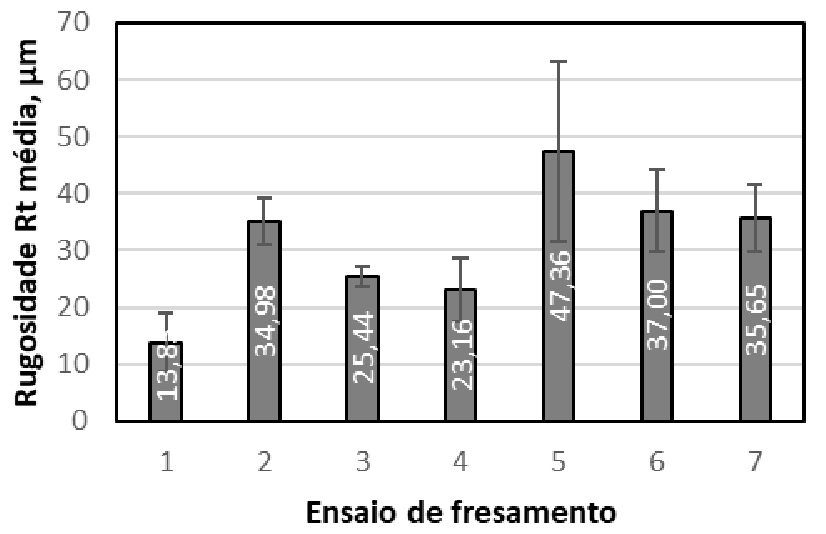

Figura 9 - Rugosidade Rt nos ensaio de fresamento.

Como verificado na Figura 9, os valores mais elevados do parâmetro Rt encontrados foram nos ensaios 5 e 6, em que foi utilizado um $a_{p}$ de $0,5 \mathrm{~mm}$. Além disso, em todos os 3 parâmetros o melhor resultado foi no ensaio número 1, em que a rotação e o $a_{p}$ utilizados foram $600 \mathrm{rpm} \mathrm{e} 1 \mathrm{~mm}$, respectivamente. Isto indica que, para melhores resultado de rugosidade Rt, deve-se evitar empregar os extremos e optar por parâmetros intermediários, principalmente com relação a rotação, como pode-se observar também nos ensaios 3 e 4 . Isto comprova o descrito por Machado (2009), onde baixas rotações podem gerar a chamada aresta postiça de corte (APC) (também denominada gume postiço) e altas rotações geram um aumento na vibração.

\subsection{Resultados da regressão linear da rugosidade}

Feitas as medições de rugosidade de cada um dos ensaios, os dados obtidos foram organizados em uma planilha eletrônica e realizadas as regressões lineares. Para se fazer tais regressões, os dados deveriam ser primeiramente organizados conforme as Equações 1 a 4 e, para que, ao aplicar a metodologia de regressão linear múltipla do software, fossem encontrados os respectivos coeficientes de regressão, para que então fossem obtidos os dados para formação das equações. Deste modo foram definidos os parâmetros X1 (Rotação), X2 (Profundidade de penetração $a_{p}$ ), X1*X2 (multiplicação entre $\mathrm{X} 1$ e X2), $\mathrm{X}^{2}, \mathrm{X} 2^{2}$. A Tabela 4 apresenta estes valores.

\begin{tabular}{|cccccc|} 
Tabela 4 - Parâmetros de regressão linear. & \\
\hline X1 (rpm) & X2 (mm) & X1*X2 & X12 & X $2^{2}$ \\
\hline 600 & 1 & 600 & 360000 & 1 \\
1000 & 1 & 1000 & 1000000 & 1 \\
800 & 1,5 & 1200 & 640000 & 2,25 \\
200 & 1 & 200 & 40000 & 1 \\
400 & 0,5 & 200 & 160000 & 0,25 \\
800 & 0,5 & 400 & 640000 & 0,25 \\
400 & 1,5 & 600 & 160000 & 2,25 \\
\hline
\end{tabular}

\subsection{Regressão linear múltipla para o parâmetro Ra}

Após organizar os dados de entrada das variáveis independentes e as variáveis dependentes de saída, foi aplicada a metodologia de regressão linear múltipla. Deste modo, foram obtidos os coeficientes de interseção da regressão linear múltipla e das variáveis independentes para o parâmetro de rugosidade $\mathrm{Ra}$. Os resultados desta regressão para o modelo da Equação 5 estão expressos nas Tabelas 5 a 7.

Tabela 5 - Coeficientes de interseção da regressão linear múltipla e das variáveis independentes do modelo de Equação 1 para o parâmetro de rugosidade Ra.

\begin{tabular}{crrrrrrrr} 
& Coeficientes & Erro padrão & \multicolumn{1}{c}{ Stat t } & valor-P & 95\% inferiores & 95\% superiores & Inferior 95,0\% & Superior 95,0\% \\
\hline Interseção & 4,365 & 1,931 & 2,260 & 0,087 & $-0,996$ & 9,726 & $-0,996$ & 9,726 \\
Variável X1 & 0,001 & 0,002 & 0,258 & 0,809 & $-0,005$ & 0,006 & $-0,005$ & 0,006 \\
Variável X2 & $-1,406$ & 1,404 & $-1,002$ & 0,373 & $-5,303$ & 2,491 & $-5,303$ & 2,491 \\
\hline
\end{tabular}

Tabela 6 - Tabela ANOVA do modelo de Equação 1 para o parâmetro Ra.

\begin{tabular}{cccccc} 
& gl & SQ & MQ & F & F de significação \\
Regressão & 2 & 2,108297333 & 1,054148667 & 0,535131981 & 0,622384607 \\
Resíduo & 4 & 7,879541524 & 1,969885381 & & \\
Total & 6 & 9,987838857 & & & \\
\hline
\end{tabular}

Tabela 7 - Estatística da regressão para o modelo de Equação 1 para o parâmetro Ra.

\begin{tabular}{ll} 
Estatística de regressão & \\
R múltiplo & 0,459441442 \\
R-Quadrado & 0,211086439 \\
R-quadrado ajustado & $-0,18337034$ \\
Erro padrão & 1,403526053 \\
Observações & 7 \\
\hline
\end{tabular}

Através destes dados (Tabela 7) é possível realizar uma análise das informações a fim de validar o processo de regressão. Para isso, analisou-se o R-quadrado ajustado, a fim de determinar a qualidade da regressão e também o valor-p, a fim de determinar a variável que mais influencia no resultado. Como o R-quadrado encontrado foi de 0,211086439, ou seja, considera-se que este modelo é uma adaptação ruim para o problema do equacionamento, uma vez que demonstra que apenas em $21 \%$ dos casos as variáveis dependentes e independentes se correlacionam desta forma. Além disso, como o menor valor-p encontrado foi de 0,373 , não é possível determinar qual a variável mais exerce influência nos resultados, uma vez que para tal a hipótese só é confirmada 
para valores igual ou inferiores a 0,05 . Em virtude disso, podese então aplicar a mesma metodologia utilizando o modelo da Equação 6. As Tabelas de 8 a 10 mostram o resultado e a variável X3 apresentada na tabela corresponde ao produto entre X1 e X2.

Tabela 8 - Coeficientes de interseção da regressão linear múltipla e das variáveis independentes do modelo de Equação 2 para o parâmetro de rugosidade Ra.

\begin{tabular}{crrrrrrrr} 
& Coeficientes & Erro padrão & Stat t & valor-P & 95\% inferiores & 95\% superiores & Inferior 95,0\% & Superior 95,0\% \\
Interseção & 5,103 & 5,328 & 0,958 & 0,409 & $-11,854$ & 22,060 & $-0,854$ & 22,060 \\
Variável X1 & $-0,001$ & 0,008 & $-0,084$ & 0,938 & $-0,027$ & 0,026 & $-0,027$ & 0,026 \\
Variável X2 & $-2,144$ & 5,105 & $-0,420$ & 0,703 & $-18,391$ & 14,103 & $-18,391$ & 14,103 \\
Variável X3 & 0,001 & 0,008 & 0,152 & 0,889 & $-0,024$ & 0,027 & $-0,024$ & 0,027 \\
\hline
\end{tabular}

Tabela 9 - Tabela ANOVA do modelo de Equação 2 para o parâmetro Ra.

\begin{tabular}{ccccccc} 
& gl & SQ & MQ & F & F de significação \\
Regressão & 3 & 2,168813 & 0,722938 & 0,277376423 & 0,839884789 \\
Resíduo & 3 & 7,819026 & 2,606342 & & \\
Total & 6 & 9,987839 & & & \\
\hline
\end{tabular}

Tabela 10 - Estatística da regressão para o modelo de Equação 2 para o parâmetro Ra.

\begin{tabular}{ll} 
Estatística de regressão & \\
\hline R múltiplo & 0,465988634 \\
R-Quadrado & 0,217145407 \\
R-quadrado ajustado & $-0,565709186$ \\
Erro padrão & 1,614416873 \\
Observações & 7 \\
\hline
\end{tabular}

Da mesma forma como feito anteriormente, pode-se analisar o resultado da regressão para o modelo de equacionamento da Equação 2. O valor R-quadrado encontrado foi de 0,217145407 (Tabela 10), que significa que apenas em aproximadamente $21,7 \%$ dos casos as variáveis se correlacionam da forma proposta pelo modelo. Além disso, ao se analisar o valor-p das variáveis independentes, observa-se que todos os valores estão muito próximos entre si e são consideravelmente maiores que 0,05. Portanto, com este resultado não é possível determinar a variável que mais influencia no resultado.

Como terceira parte da análise feita para o parâmetro de rugosidade $\mathrm{Ra}$, repetiu-se a metodologia apresentada. Entretanto, nesta análise foi utilizado o modelo de equacionamento descrito pela Equação 3. Nas Tabelas 11 a 13, estão expressos os resultados. As variáveis X3 e X4 descritas na Tabela 11 são os quadrado de X1 e X2 respectivamente.

Tabela 11 - Coeficientes de interseção da regressão linear múltipla e das variáveis independentes do modelo de Equação 3 para o parâmetro de rugosidade Ra.

\begin{tabular}{crrrrrrrr} 
& Coeficientes & Erro padrão & Stat t & valor-P & $95 \%$ inferiores & $95 \%$ superiores & Inferior 95,0\% & Superior 95,0\% \\
Interseção & 12,844 & 6,445 & 1,993 & 0,184 & $-14,888$ & 40,577 & $-14,888$ & 40,577 \\
Variável X 1 & $-0,010$ & 0,012 & $-0,822$ & 0,497 & $-0,061$ & 0,041 & $-0,061$ & 0,041 \\
Variável X 2 & $-15,733$ & 9,554 & $-1,647$ & 0,241 & $-56,839$ & 25,372 & $-56,839$ \\
Variável X 3 & 0,000 & 0,000 & 0,935 & 0,449 & 0,000 & 0,000 & $-0,000$ & 25,372 \\
Variável X 4 & 7,046 & 4,764 & 1,479 & 0,277 & $-13,452$ & 27,543 & $-13,452$ & 0,000 \\
\hline
\end{tabular}

Tabela 12 - Tabela ANOVA do modelo de Equação 3 para o parâmetro Ra.

\begin{tabular}{cl|rrrr} 
& gl & SQ & MQ & F & F de significação \\
Regressão & 4 & 6,722342457 & 1,680585614 & 1,029298709 & 0,546999989 \\
Resíduo & 2 & 3,2654964 & 1,6327482 & & \\
Total & 6 & 9,987838857 & & & \\
\hline
\end{tabular}

Tabela 13 - Estatística da regressão para o modelo de Equação 3 para o parâmetro Ra.

\begin{tabular}{ll} 
Estatística de regressão & \\
R múltiplo & 0,820397925 \\
R-Quadrado & 0,673052755 \\
R-quadrado ajustado & 0,019158264 \\
Erro padrão & 1,277790358 \\
Observações & 7 \\
\hline
\end{tabular}

Analisando-se os resultados deste modelo matemático, pôde-se encontrar um R-quadrado de 0,673052755 (Tabela 13), ou seja, aproximadamente $67,3 \%$ dos casos as variáveis irão se correlacionar conforme descrito pelo modelo. Além disso, obteve-se um menor valor-p das variáveis independentes de 0,241, que é maior do que 0,05. Portanto, apesar deste valor ser aproximadamente metade do valor correspondente à variável X1, não se pode considerar que a variável X2 apresenta uma maior influência no resultado, uma vez que este valor continua sendo maior que o valor base definido.

Considerando-se o quarto modelo de equacionamento descrito pela Equação 4, foi realizada um último processo de regressão para o parâmetro de rugosidade $\mathrm{Ra}$, utilizando a mesma metodologia descrita nos casos anteriores. Assim, os resultados da regressão podem ser observados nas Tabelas de 14 a 16. Vale considerar que as variáveis X3, X4 e X5 apresentadas na Tabela 14 são respectivamente o produto entre $\mathrm{X} 1$ e X2, o quadrado de X1 e o quadrado de X2. 
O quarto modelo de regressão do parâmetro de rugosidade $\mathrm{Ra}$ fornece um R-quadrado de 0,636698918 (Tabela 16), o que significa que em aproximadamente $63,67 \%$ dos casos as variáveis se correlacionam conforme descrito pelo modelo de equacionamento utilizado. Ademais, o menor valorp encontrado foi de 0,462 . Portanto, não é possível determinar a variável que mais influencia o resultado.

Tabela 14 - Coeficientes de interseção da regressão linear múltipla e das variáveis independentes do modelo de Equação 4 para o parâmetro de rugosidade Ra.

\begin{tabular}{crrrrrrrr} 
& Coeficientes & Erro padrão & Stat t & valor-P & $95 \%$ inferiores & $95 \%$ superiores & Inferior 95,0\% & Superior 95,0\% \\
Interseção & 14,211 & 11,041 & 1,287 & 0,420 & $-126,075$ & 154,497 & $-126,075$ & 154,497 \\
Variável X1 & $-0,012$ & 0,020 & $-0,581$ & 0,665 & $-0,267$ & 0,244 & $-0,267$ & 0,244 \\
Variável X2 & $-17,178$ & 15,239 & $-1,127$ & 0,462 & $-210,809$ & 176,453 & $-210,809$ & 176,453 \\
Variável X3 & 0,001 & 0,010 & 0,129 & 0,918 & $-0,120$ & 0,122 & $-0,120$ & 0,122 \\
Variável X4 & 0,000 & 0,000 & 0,627 & 0,643 & $-0,000$ & 0,000 & $-0,000$ & 0,000 \\
Variável X5 & 7,517 & 6,999 & 1,074 & 0,477 & $-81,414$ & 96,448 & $-81,414$ & 96,448 \\
\hline
\end{tabular}

Tabela 15 - Tabela ANOVA do modelo de Equação 4 para o parâmetro Ra.

\begin{tabular}{cccccc} 
& gl & SQ & MQ & F & F de significação \\
Regressão & 5 & 6,359246 & 1,271849 & 0,350507581 & 0,847999158 \\
Resíduo & 1 & 3,628593 & 3,628593 & & \\
Total & 6 & 9,987839 & & & \\
\hline
\end{tabular}

Tabela 16 - Estatística da regressão para o modelo de Equação 4 para o parâmetro Ra.

\begin{tabular}{ll}
\hline \multicolumn{2}{l}{ Estatística de regressão } \\
R múltiplo & 0,797934156 \\
R-Quadrado & 0,636698918 \\
R-quadrado ajustado & $-1,179806494$ \\
Erro padrão & 1,904886523 \\
Observações & 7 \\
\hline
\end{tabular}

Assim, considerando os coeficientes encontrados através da metodologia de regressão utilizando os 4 modelos de equacionamento, obtém-se as Equações 10 a 13, para correlacionar os dados de entrada das variáveis independentes rotação (X1) e profundidade de penetração $a_{p}(X 2)$ com a variável dependente de saída $\mathrm{Ra}$.

$$
\begin{aligned}
& R a=4,365+0,001 x_{1}-1,406 x_{2} \\
& R a=5,103-0,001 x_{1}-2,144 x_{2}+0,001 x_{1} x_{2} \\
& R a=12,844-0,010 x_{1}-15,733 x_{2}+7,046 x^{2}{ }_{2} \\
& R a=14,211-0,012 x_{1}-17,178 x_{2}+0,001 x_{1} x_{2}+7,517 x^{2}{ }_{2}
\end{aligned}
$$

\subsection{Regressão Linear Múltipla para o Parâmetro Rz}

Da mesma forma que foi feita para o parâmetro de rugosidade $\mathrm{Ra}$, repete-se processo de regressão linear múltipla para o parâmetro Rz. Desta forma, após se aplicar a metodologia, foi possível obter os resultados da regressão para o modelo de equacionamento apresentado pela Equação 1. Assim, os resultados são apresentados pelas Tabelas 17 a 19.

Tabela 17 - Coeficientes de interseção da regressão linear múltipla e das variáveis independentes do modelo de Equação 1 para o parâmetro de rugosidade $R z$.

\begin{tabular}{crrrrrrrr}
\hline & Coeficientes & Erro padrão & Stat t & valor-P & 95\% inferiores & 95\% superiores & Inferior 95,0\% & Superior 95,0\% \\
\hline Interseção & 27,542 & 11,353 & 2,426 & 0,072 & $-3,978$ & 59,061 & $-3,978$ & 59,061 \\
Variável X1 & 0,002 & 0,012 & 0,162 & 0,879 & $-0,031$ & 0,035 & $-0,031$ & 0,035 \\
Variável X2 & $-7,944$ & 8,252 & $-0,963$ & 0,390 & $-30,854$ & 14,966 & $-30,854$ & 14,966 \\
\hline
\end{tabular}

Tabela 18 - Tabela ANOVA do modelo de Equação 1 para o parâmetro Rz.

\begin{tabular}{ccrrrr}
\hline & gl & \multicolumn{1}{c}{ SQ } & MQ & F & F de significação \\
Regressão & 2 & 64,8920 & 32,446 & 0,476533 & 0,652186175 \\
Resíduo & 4 & 272,3502 & 68,08756 & & \\
Total & 6 & 337,2422 & & & \\
\hline
\end{tabular}

Tabela 19 - Estatística da regressão para o modelo de Equação 1 para o parâmetro Rz.

\begin{tabular}{ll} 
Estatística de regressão & \\
R múltiplo & 0,438656534 \\
R-Quadrado & 0,192419555 \\
R-quadrado ajustado & $-0,211370667$ \\
Erro padrão & 8,251518593 \\
Observações & 7 \\
\hline
\end{tabular}

Após os resultados serem analisados, pode-se observar um R-quadrado de 0,192419555 (Tabela 19), ou seja, as variáveis se correlacionam da forma apresentada pelo modelo em aproximadamente 19,2\% dos casos. Além disso, com um menor valor-p entre as variáveis de 0,390 , não é possível determinar a variável de maior influência para a resposta. Da mesma forma, utilizando o modelo apresentado pela Equação 2 , repete-se a metodologia a fim de se encontrar os coeficientes 
de interseção e das variáveis independentes. Os resultados da regressão estão expressos nas Tabelas 20 a 22.

Utilizando o modelo de equacionamento descrito pela Equação 6, não houveram melhores significativas na modelagem. O R-quadrado encontrado foi de 0,193965281
(Tabela 22), que significa que em apenas aproximadamente $19,4 \%$ dos casos as variáveis se correlacionam da forma proposta por esta equação. Além disso, continua sendo impossível determinar a variável que mais influencia no resultado, uma vez que o menor valor-p para as variáveis encontrado foi de 0,759 , que é maior que 0,05 .

Tabela 20 - Coeficientes de interseção da regressão linear múltipla e das variáveis independentes do modelo de Equação 2 para o parâmetro de rugosidade $R z$.

\begin{tabular}{crrrrrrrr} 
& Coeficientes & Erro padrão & Stat t & valor-P & $95 \%$ inferiores & $95 \%$ superiores & Inferior 95,0\% & Superior 95,0\% \\
Interseção & 29,708 & 31,417 & 0,946 & 0,414 & $-70,274$ & 129,689 & $-70,274$ & 129,689 \\
Variável X1 & $-0,002$ & 0,050 & $-0,034$ & 0,975 & $-0,159$ & 0,156 & $-0,159$ & 0,156 \\
Variável X2 & $-10,110$ & 30,101 & $-0,336$ & 0,759 & $-105,906$ & 85,686 & $-105,906$ \\
Variável X3 & 0,004 & 0,048 & 0,076 & 0,944 & $-0,148$ & 0,155 & $-0,148$ & 85,686 \\
\hline
\end{tabular}

Tabela 21 - Tabela ANOVA do modelo de Equação 2 para o parâmetro Rz.

\begin{tabular}{cccccr} 
& gl & SQ & MQ & F & F de significação \\
Regressão & 3 & 65,41328533 & 21,80442844 & 0,240641347 & 0,863733281 \\
Resíduo & 3 & 271,8289524 & 90,60965079 & & \\
Total & 6 & 337,2422377 & & & \\
\hline
\end{tabular}

Tabela 22 - Estatística da regressão para o modelo de Equação 2 para o parâmetro Rz.

\begin{tabular}{ll} 
Estatística de regressão & \\
R múltiplo & 0,440414896 \\
R-Quadrado & 0,193965281 \\
R-quadrado ajustado & $-0,612069438$ \\
Erro padrão & 9,518910168 \\
Observações & 7 \\
\hline
\end{tabular}

Assim, dando continuidade, parte-se para a aplicação do modelo de equacionamento descrito pela Equação 3. Os resultados obtidos estão expressos nas Tabelas 23 a 25 . Analisando os dados fornecidos pela regressão e pela estatística da regressão, para o modelo de equacionamento proposto pela Equação 3, as variáveis se correlacionam conforme o proposto em aproximadamente 70,9\% dos casos, uma vez que o R-quadrado encontrado foi de 0,708958764 (Tabela 25). Além disso, continua sendo impossível determinar a variável que mais influencia no resultado, uma vez que o menor valor-p das variáveis foi de 0,202 , que continua sendo maior que 0,05 .

Tabela 23 - Coeficientes de interseção da regressão linear múltipla e das variáveis independentes do modelo de Equação 3 para o parâmetro de rugosidade Rz.

\begin{tabular}{crrrrrrrr} 
& Coeficientes & Erro padrão & Stat t & valor-P & 95\% inferiores & $95 \%$ superiores & Inferior 95,0\% & Superior 95,0\% \\
Interseção & 81,000 & 35,337 & 2,292 & 0,149 & $-71,041$ & 233,041 & $-71,041$ & 233,041 \\
Variável X1 & $-0,064$ & 0,065 & $-0,976$ & 0,432 & $-0,345$ & 0,217 & $-0,345$ & 0,217 \\
Variável X2 & $-97,967$ & 52,377 & $-1,870$ & 0,202 & $-323,326$ & 127,393 & $-323,326$ \\
Variável X3 & 0,000 & 0,000 & 1,081 & 0,393 & 0,000 & 0,000 & 0,000 & 0,000 \\
Variável X4 & 44,427 & 26,118 & 1,701 & 0,231 & $-67,949$ & 156,804 & $-67,949$ & 156,804 \\
\hline
\end{tabular}

Tabela 24 - Tabela ANOVA do modelo de Equação 3 para o parâmetro Rz.

\begin{tabular}{ccrrrr} 
& gl & \multicolumn{1}{c}{ SQ } & MQ & F & F de significação \\
Regressão & 4 & 239,0908401 & 59,77271003 & 1,217969616 & 0,497377471 \\
Resíduo & 2 & 98,1513976 & 49,0756988 & & \\
Total & 6 & 337,2422377 & & & \\
\hline
\end{tabular}

Tabela 25 - Estatística da regressão para o modelo de Equação 3 para o parâmetro Rz.

\begin{tabular}{ll} 
Estatística de regressão & \\
R múltiplo & 0,841996891 \\
R-Quadrado & 0,708958764 \\
R-quadrado ajustado & 0,126876293 \\
Erro padrão & 7,00540497 \\
Observações & 7 \\
\hline
\end{tabular}

Partindo para a última modelagem do parâmetro de rugosidade $\mathrm{Rz}$, foi utilizado o modelo de equacionamento proposto pela Equação 4 e a mesma metodologia já descrita.
Assim, os resultados da regressão, bem como sua estatística, estão expressos nas Tabelas 26 a 38 .

A resposta da modelagem para o parâmetro de rugosidade $\mathrm{Rz}$ utilizando o modelo de equacionamento proposto pela Equação 8 fornece um R-quadrado de 0,675358527 (Tabela 28). Assim, de acordo com o modelo, as variáveis se correlacionam da forma proposta em cerca de $67,5 \%$ dos casos. Além disso, com um menor valor-p, das variáveis, encontrado igual a 0,433 , não é possível determinar qual é a mais influente no resultado, visto que este valor é maior que 0,05 . 
Tabela 26 - Coeficientes de interseção da regressão linear múltipla e das variáveis independentes do modelo de Equação 4 para o parâmetro de rugosidade Rz.

\begin{tabular}{crrrrrrrr}
\hline \hline & Coeficientes & Erro padrão & Stat t & valor-P & 95\% inferiores & 95\% superiores & Inferior 95,0\% & Superior 95,0\% \\
Interseção & 86,680 & 0,646 & 1,429 & 0,389 & $-683,900$ & 857,261 & $-683,900$ & 857,261 \\
Variável X1 & $-0,071$ & 0,110 & $-0,645$ & 0,635 & $-1,475$ & 1,332 & $-1,475$ & 1,332 \\
Variável X2 & $-103,636$ & 83,707 & $-1,238$ & 0,433 & $-1.167,237$ & 959,965 & $-1.167,237$ & 959,965 \\
Variável X3 & 0,004 & 0,052 & 0,069 & 0,956 & $-0,661$ & 0,668 & $-0,661$ & 0,668 \\
Variável X4 & 0,000 & 0,000 & 0,724 & 0,601 & $-0,001$ & 0,001 & $-0,001$ & 0,001 \\
Variável X5 & 46,763 & 38,445 & 1,216 & 0,438 & $-441,727$ & 535,253 & $-441,727$ & 535,253 \\
\hline
\end{tabular}

Tabela 27 - Tabela ANOVA do modelo de Equação 4 para o parâmetro Rz.

\begin{tabular}{c|ccccc} 
& gl & SQ & MQ & F & F de significação \\
Regressão & 5 & 227,759421 & 45,55188421 & 0,416064234 & 0,818241541 \\
Resíduo & 1 & 109,4828167 & 109,4828167 & & \\
Total & 6 & 337,2422377 & & & \\
\hline
\end{tabular}

Tabela 28 - Estatística da regressão para o modelo de Equação 4 para o parâmetro $R$.

\begin{tabular}{ll} 
Estatística de regressão & \\
R múltiplo & 0,821802 \\
R-Quadrado & 0,675358527 \\
R-quadrado ajustado & $-0,947848835$ \\
Erro padrão & 10,46340368 \\
Observações & 7 \\
\hline
\end{tabular}

Assim, considerando os coeficientes encontrados através da metodologia de regressão utilizando os 4 modelos de equacionamento, obtém-se as Equações 13 a 16, para correlacionar os dados de entrada das variáveis independentes rotação (X1) e profundidade de penetração $a_{p}(X 2)$ com a variável dependente de saída Rz.
$R z=27,542+0,002 x_{1}-7,944 x_{2}$

$R z=29,708-0,002 x_{1}-10,110 x_{2}+0,004 x_{1} x_{2}$

$R z=81,000-0,064 x_{1}-97,967 x_{2}+44,427 x_{2}{ }^{2}$

$R z=86,680-0,071 x_{1}-103,636 x_{2}+0,004 x_{1} x_{2}+46,763 x_{2}^{2}$

\subsection{Regressão linear múltipla para o parâmetro $R t$}

Nesta seção são apresentados os resultados da regressão do parâmetro de rugosidade $\mathrm{Rt}$ para o modelo de equacionamento apresentado pela Equação 1. Estes resultados são apresentados pelas Tabelas 29 a 31.

Tabela 29 - Coeficientes de interseção da regressão linear múltipla e das variáveis independentes do modelo de Equação 1 para o parâmetro de rugosidade Rt.

\begin{tabular}{crrrrrrrr} 
& Coeficientes & Erro padrão & Stat t & valor-P & $95 \%$ inferiores & 95\% superiores & Inferior 95,0\% & Superior 95,0\% \\
Interseção & 41,926 & 16,733 & 2,506 & 0,066 & $-4,531$ & 88,384 & $-4,531$ & 88,384 \\
Variável X1 & 0,001 & 0,018 & 0,073 & 0,945 & $-0,047$ & 0,050 & $-0,047$ & 0,050 \\
Variável X2 & $-11,633$ & 12,162 & $-0,956$ & 0,393 & $-45,400$ & 22,134 & $-45,400$ & 22,134 \\
\hline
\end{tabular}

Tabela 30 - Tabela ANOVA do modelo de Equação 1 para o parâmetro Rt.

\begin{tabular}{c|ccccc} 
& gl & SQ & MQ & F & F de significação \\
Regressão & 2 & 136,1141453 & 68,05707267 & 0,460103152 & 0,660926791 \\
Resíduo & 4 & 591,6679541 & 147,9169885 & & \\
Total & 6 & 727,7820994 & & & \\
\hline
\end{tabular}

Tabela 31 - Estatística da regressão para o modelo de Equação 1 para o parâmetro Rt.

\begin{tabular}{ll} 
Estatística de regressão & \\
R múltiplo & 0,43246498 \\
R-Quadrado & 0,187025959 \\
R-quadrado ajustado & $-0,219461061$ \\
Erro padrão & 12,16211283 \\
Observações & 7 \\
\hline
\end{tabular}

A partir dos resultados apresentados nas Tabelas 29 a 31, foi possível encontrar um R-quadrado no valor de 0,187025959 (Tabela 31), ou seja, em aproximadamente
$18,7 \%$ dos casos as variáveis se correlacionam conforme proposto pelo modelo de equacionamento da Equação 1. Ademais, o menor valor-p obtido foi de 0,393, que é maior que 0,05 . Portanto não é possível determinar a variável que mais influencia no resultado.

A partir desta etapa, parte-se para a aplicação do modelo proposto pela Equação 2. Os resultados da regressão linear para este modelo estão apresentados nas tabelas 32 a 34 . Logo, com os dados dos resultados da regressão disponíveis, observa-se que, pelo equacionamento proposto pela Equação 2 para o parâmetro de rugosidade $\mathrm{Rt}$, as variáveis se correlacionam desta forma em apenas em 18,7\% dos casos, 
uma vez que o R-quadrado encontrado foi de 0,187033688

(Tabela 34). Além disso, o menor valor-p encontrado foi de
0,807, que é maior que 0,05 , o que impossibilita a determinação de qual variável é mais influente no processo.

Tabela 32 - Coeficientes de interseção da regressão linear múltipla e das variáveis independentes do modelo de Equação 2 para o parâmetro de rugosidade Rt.

\begin{tabular}{crrrrrrrr} 
& Coeficientes & Erro padrão & \multicolumn{1}{c}{ Stat t } & valor-P & 95\% inferiores & $95 \%$ superiores & Inferior 95,0\% & Superior 95,0\% \\
Interseção & 42,151 & 46,350 & 0,909 & 0,430 & $-105,354$ & 189,657 & $-105,354$ & 189,657 \\
Variável X1 & 0,001 & 0,073 & 0,012 & 0,991 & $-0,232$ & 0,233 & $-0,232$ & 0,233 \\
Variável X2 & $-11,858$ & 44,410 & $-0,267$ & 0,807 & $-153,189$ & 129,473 & $-153,189$ & 129,473 \\
Variável X3 & 0,000 & 0,070 & 0,005 & 0,996 & $-0,223$ & 0,224 & $-0,223$ & 0,224 \\
\hline
\end{tabular}

Tabela 33 - Tabela ANOVA do modelo de Equação 2 para o parâmetro Rt.

\begin{tabular}{cccccr} 
& gl & SQ & MQ & F & F de significação \\
Regressão & 3 & 136,1197703 & 45,37325678 & 0,23006327 & 0,870664657 \\
Resíduo & 3 & 591,6623291 & 197,2207764 & & \\
Total & 6 & 727,7820994 & & & \\
\hline
\end{tabular}

Tabela 34 - Estatística da regressão para o modelo de Equação 2 para o parâmetro Rt.

\begin{tabular}{ll} 
Estatística de regressão & \\
\hline R múltiplo & 0,432473916 \\
R-Quadrado & 0,187033688 \\
R-quadrado ajustado & $-0,625932623$ \\
Erro padrão & 14,04353148 \\
Observações & 7 \\
\hline
\end{tabular}

Nas Tabelas de 35 a 37 são apresentados os resultados da aplicação da regressão linear utilizando-se a Equação 3 como modelo de equacionamento.

Analisando os resultados para o modelo de equacionamento proposto pela Equação 3, obtém-se um Rquadrado no valor de 0,782792538 (Tabela 37). Isso significa que, as variáveis se correlacionam da forma proposta em aproximadamente $78,3 \%$ dos casos. Além disso, o menor valor-p encontrado foi de 0,142 . Portanto, como este valor é maior que 0,05 , não é possível determinar qual variável influencia mais no processo.

Tabela 35 - Coeficientes de interseção da regressão linear múltipla e das variáveis independentes do modelo de Equação 3 para o parâmetro de rugosidade Rt.

\begin{tabular}{crrrrrrrr} 
& Coeficientes & Erro padrão & Stat t & valor-P & $95 \%$ inferiores & $95 \%$ superiores & Inferior 95,0\% & Superior 95,0\% \\
Interseção & 129,258 & 44,845 & 2,882 & 0,102 & $-63,694$ & 322,210 & $-63,694$ & 322,210 \\
Variável X1 & $-0,108$ & 0,083 & $-1,298$ & 0,324 & $-0,464$ & 0,249 & $-0,464$ & 0,249 \\
Variável X2 & $-157,335$ & 66,471 & $-2,367$ & 0,142 & $-443,335$ & 128,664 & $-443,335$ & 128,664 \\
Variável X3 & 0,000 & 0,000 & 1,398 & 0,297 & $-0,000$ & 0,000 & $-0,000$ & 0,000 \\
Variável X4 & 72,187 & 33,146 & 2,178 & 0,161 & $-70,429$ & 214,802 & $-70,429$ & 214,802 \\
\hline
\end{tabular}

Tabela 36 - Tabela ANOVA do modelo de Equação 3 para o parâmetro Rt.

\begin{tabular}{cccrrr} 
& gl & SQ & MQ & F & F de significação \\
Regressão & 4 & 569,702397 & 142,4255993 & 1,801946703 & 0,387235842 \\
Resíduo & 2 & 158,0797024 & 79,0398512 & & \\
Total & 6 & 727,7820994 & & & \\
\hline
\end{tabular}

Tabela 37 - Estatística da regressão para o modelo de Equação 3 para o parâmetro Rt.

\begin{tabular}{ll} 
Estatística de regressão \\
R múltiplo & 0,884755638 \\
R-Quadrado & 0,782792538 \\
R-quadrado ajustado & 0,348377615 \\
Erro padrão & 8,89043594 \\
Observações & 7 \\
\hline
\end{tabular}

Os resultados da reaplicação da metodologia empregando-se a Equação 4 da regressão linear múltipla do parâmetro de rugosidade Rt são apresentados nas Tabelas 38 a 40. O quarto modelo de regressão do parâmetro de rugosidade Rt fornece um R-quadrado de 0,759628052 (Tabela 40), o que significa que em aproximadamente $75,96 \%$ dos casos as variáveis se correlacionam conforme descrito pelo modelo de equacionamento utilizado. Ademais, o menor valor-p encontrado foi de 0,367 . Portanto, não é possível determinar a variável que mais influencia o resultado.

Considerando os coeficientes encontrados através da metodologia de regressão utilizando os 4 modelos de equacionamento, obtém-se as Equações 18 a 21. Estas equações correlacionam os dados de entrada das variáveis independentes - rotação $(\mathrm{X} 1)$ e profundidade de penetração $a_{p}$ (X2) - com a variável dependente de saída - rugosidade Rt.

$$
R t=41,926+0,001 x_{1}-11,633 x_{2}
$$

$R t=42,151+0,001 x_{1}-11,858 x_{2}$

$R t=129,258-0,108 x_{1}-157,335 x_{2}+72,187 x_{2}^{2}$

$R t=134,029-0,113 x_{1}-161,564 x_{2}+74,844 x_{2}^{2}$ 
Tabela 38 - Coeficientes de interseção da regressão linear múltipla e das variáveis independentes do modelo de Equação 4 para o parâmetro de rugosidade Rt.

\begin{tabular}{crr|rrrrrrr}
\hline & Coeficientes & Erro padrão & Stat t & valor-P & 95\% inferiores & 95\% superiores & Inferior 95,0\% & Superior 95,0\% \\
Interseção & 134,029 & 76,661 & 1,748 & 0,331 & $-840,035$ & $1.108,093$ & $-840,035$ & $1.108,093$ \\
Variável X1 & $-0,113$ & 0,140 & $-0,811$ & 0,566 & $-1,888$ & 1,661 & $-1,888$ & 1,661 \\
Variável X2 & $-161,546$ & 105,811 & $-1,527$ & 0,369 & $-1.506,008$ & $1.182,916$ & $-1.506,008$ & $1.182,916$ \\
Variável X3 & 0,000 & 0,066 & 0,006 & 0,996 & $-0,840$ & 0,841 & $-0,840$ & 0,841 \\
Variável X4 & 0,000 & 0,000 & 0,940 & 0,520 & $-0,001$ & 0,001 & $-0,001$ & 0,001 \\
Variável X5 & 74,844 & 48,597 & 1,540 & 0,367 & $-542,639$ & 692,327 & $-542,639$ & 692,327 \\
\hline
\end{tabular}

Tabela 39 - Tabela ANOVA do modelo de Equação 4 para o parâmetro Rt

\begin{tabular}{cccccc} 
& gl & SQ & MQ & F & F de significação \\
Regressão & 5 & 552,8436988 & 110,5687398 & 0,632043847 & 0,736005547 \\
Resíduo & 1 & 174,9384007 & 174,9384007 & & \\
Total & 6 & 727,7820994 & & & \\
\hline
\end{tabular}

Tabela 40 - Estatística da regressão para o modelo de Equação 4 para o parâmetro Rt

\begin{tabular}{ll}
\hline \multicolumn{2}{l}{ Estatística de regressão } \\
\hline R múltiplo & 0,871566436 \\
R-Quadrado & 0,759628052 \\
R-quadrado ajustado & $-0,442231686$ \\
Erro padrão & 13,22642811 \\
Observações & 7 \\
\hline
\end{tabular}

\subsection{Discussão}

Após a realização dos experimentos e posterior análise dos resultados, pôde-se encontrar como melhores alternativas para a tentativa de prever os resultados da rugosidade no processo de fresamento do aço ABNT 1020 em relação aos parâmetros de entrada do processo. Assim, para cada parâmetro de rugosidade avaliado as equações que melhor representam a correlação das variáveis de entrada com as variáveis de saída são as Equações 12 (para a rugosidade Ra), 16 (para a rugosidade $\mathrm{Rz}$ ) e 20 (para o parâmetro Rt):

$R a=12,844-0,010 x_{1}-15,733 x_{2}+7,046 x^{2}{ }_{2}$

$R z=81,000-0,064 x_{1}-97,967 x_{2}+44,427 x_{2}^{2}$

$R t=129,258-0,108 x_{1}-157,335 x_{2}+72,187 x_{2}{ }^{2}$

Entretanto, como as equações apresentadas possuem uma assertividade de 67,3\% (Equação 12), 70,9\% (Equação 16) e $78,3 \%$, Equação (20) pode-se concluir que, apesar possuírem um R-quadrado maior de $60 \%$, este resultado pode ser considerado não aceitável considerando o objetivo deste trabalho, uma vez que valores aceitáveis do R-quadrado giram em torno de $95 \%$, o que o torna inviável para o caso do fresamento.

Deve-se consideram que o processo de otimização dos parâmetros de corte na usinagem é majoritariamente empírico e muitas vezes estocástico, o que é corroborado estatisticamente pelos resultados obtidos. Uma das hipóteses que possa justificar os resultados é a baixa quantidade de ensaios proposta pelo planejamento experimental Doehlert aplicado no processo de usinagem por fresamento. Os resultados não comprovam a impossibilidade de se mapear e prever os resultados de rugosidade no processo de fresamento. Entretanto, há de se levar em conta que, por ser um trabalho empírico, uma grande quantidade de ensaios, bem como a análise de uma maior quantidade de parâmetros permitiria uma análise mais criteriosa e, portanto, um provável resultado satisfatório.

Com relação aos parâmetros utilizados, não foi utilizado o avanço, que é mais usual neste tipo de análise. Isso se deve ao fato de a máquina ferramenta utilizadas não ser totalmente digital. A fresadora disponível no Labenge empregada neste trabalho possui um ajuste analógico do avanço da mesa. Este avanço é zerado através de um mecanismo que utiliza um potenciômetro e que não indica o valor configurado, apenas níveis de avanço. Assim, este tipo de ajuste não fornece a precisão requerida para a análise estatística feita neste trabalho.

\section{CONCLUSÕES}

Foram realizados ensaios de fresamento no aço ABNT 1020 variando-se os parâmetros de entrada visando obter-se um modelo matemático para caracterizar o comportamento dos parâmetros Ra, Rz e Rt. Para tal, foi utilizada a metodologia de planejamento experimental Doehlert como forma orientação para de obtenção dos dados necessários. Com os resultados alcançados neste trabalho, conclui-se que:

- A utilização da metodologia de regressão linear múltipla aliada ao planejamento experimental Doehlert provou-se não ser o método mais eficiente para o caso do processo de fresamento. Isto decorre do fato dos parâmetros de R-quadrado obtidos serem relativamente menores que os esperados e apresentados em outras referências (Gonçalves, 2015; Rodrigues, 2018);

- Apesar dos resultados não estarem de acordo com as recomendações de outras referências (Goncalves, 2015; Teófilo, 2006), em caso de utilização das equações determinadas neste trabalho, as mais adequadas foram as Equações 12, 16 e 20.

- O planejamento experimental Doehlert, como utilizado, é considerado pouco eficiente ao considerar o objetivo deste trabalho. Isto deve-se ao número consideravelmente reduzido que este planejamento 
experimental propõe. Além disso, para que se obtenha uma assertividade adequada, é recomendado que a metodologia de planejamento experimental de Doehlert seja adaptada, realizando repetições no ponto central, ampliando assim a quantidade de dados para sustentar a regressão. Outra possível solução seria a utilização de uma metodologia mais completa, com um número elevado de ensaios. Adotar uma maior quantidade de parâmetros a serem analisados pode levar à uma análise mais completa e que, possivelmente, contribuirá para uma solução satisfatória do problema apresentado neste.

\section{R E FER E N C I A S}

ASSOCIAÇÃO BRASILEIRA DE NORMAS TÉCNICAS. Aços Carbono e Ligados para Construção Mecânica Designação e Composição Química, NBR NM 87/2000. Rio de Janeiro, 2000.

ASSOCIAÇÃO BRASILEIRA DE NORMAS TÉCNICAS. Especificações Geométricas do Produto (GPS), Rugosidade: Método do perfil - termos, definições e parâmetros da rugosidade, NBR ISO 4287. Rio de Janeiro, 2002.

AGOSTINHO, O. L.; RODRIGUES, A. C. S.; LIRANI, J. Tolerâncias, Ajustes, Desvios e Análise de Dimensões. São Paulo: Edgard Blucher, 2004.

CHIAVERINI, V. Tecnologia Mecânica: Processos de fabricação e tratamento. $2^{a}$ edição. Volume 2. São Paulo: McGraw-Hill, 1986.

DINIZ, A. E.; MARCONDES, F. C.; COPPINI, N. L. Tecnologia da Usinagem dos Materiais. $7^{a}$ edição. São Paulo: Art Liber Ltda, 2010.

DOEHLERT, D. H. Uniform Shell Designs. Journal Of The Royal Statistical Society, Londres, v. 19, n. 3, p.231239, 1970

DROZDA, T. J.; WICK, C. Tools and manufacturing engineer's handbook - Machining. SME. pp.21-40, 1983.

FABRINO, H. J. F. Emprego de Otimização Multivariada no Desenvolvimento de Métodos para Determinação de Metais de Interesse em Soro e Sangue Humanos por Espectrometria de Absorção Atômica em Forno de Grafite. 2008. 106 f. Dissertação (Mestrado em Química) - Universidade Federal de Minas Gerais, MG, 2008.

FERRARESI, D. Fundamentos da Usinagem dos Metais. $4^{\mathrm{a}}$ edição. São Paulo: Edgard Blucher, 1977.

FREITAS, M. T. T. Estudo das condições de corte no resultado de trabalho do processo de torneamento do aço abnt 1020. 2015. 69 f. Monografia (Graduação em Engenharia Mecânica) - Universidade Federal de Viçosa, MG, 2015.

GONÇALVES, R.S. et al. Análise da Rugosidade em Função do Avanço e Velocidade de Corte Utilizando o Fluido de Corte Óleo Vegetal. Congresso Brasileiro de Engenharia de Fabricação. $8^{\text {a }}$ edição. 2015. Salvador BA.

GROOVER, M. P. Fundamentos da Moderna Manufatura. 5 edição. Volume 1. Rio de Janeiro: Ltc, 2017.

JUNEJA, B. L., SWKHON, G. S. Fundamentals of metal cutting and machine tools. Nova Délhi: John Wiley \& Sons, 1987.

KALPAKJIAN, S. Manufacturing engeneering and technology. $3^{\text {a }}$ edition. Nova York: Addison-Wesley Publishing Co., 1995.

MACHADO, A. R. et al. Teoria da Usinagem dos Materiais. $1^{\text {a }}$ edição. São Paulo: Edgard Blucher, 2009.

MONTGOMERY, D. C.; RUNGER, G. C. Estatística Aplicada e Probabilidade Para Engenheiros. 4. ed. Rio de Janeiro: Ltc, 2009. $490 \mathrm{p}$.

NOVAES, C. G. et al. Otimização de Métodos Analíticos Usando Metodologia de Superfícies De Resposta - Parte I: Variáveis de Processo. Revista Virtual de Química, v. 9, p. 32, 2017. ISSN 1984-6835.

RODRIGUES, J. R. P. et al. Correlations analisys of the roughness as function of cutting speed and feed rate (the roughness as function of machining parameters). Acta Scientarium, v. 41, 2018. ISSN 1807-8664

ROSA, L. C. Acabamento de superfícies - Rugosidade da Superfície. Apostila de curso. Oficina Mecânica de Automação. UNESP. 2006.

SATA, T. Surface finish in metal cutting, Annals of the CIRP. v. 12. n. 4. pp.190-197, 1963.

SCHAFFER, G. H. The many faces of surface texture. American Machinist: and Automated Manufacturing, 1988.

SHAW, M. C. Metal cutting principles. Oxfort Science Publication, 1984.

TEÓFILO, R. F.; FERREIRA, M. M. C. Quimiometria II: Planilhas Eletrônicas para Cálculos de Planejamentos Experimentais, um Tutorial, Quim. Nova v. 29, p. 338, 2006. 